\title{
Altered Immune Activation and IL-23 Signaling in Response to Candida albicans in Autoimmune Polyendocrine Syndrome Type 1
}

\author{
Øyvind Bruserud', Eirik Bratland', Alexander Hellesen', Nicolas Delaleu ${ }^{2,3,4}$, \\ Håkon Reikvam ${ }^{5}$, Bergithe E. Oftedal ${ }^{1}$ and Anette S. B. Wolff' ${ }^{1 *}$ \\ ${ }^{1}$ Department of Clinical Science, University of Bergen, Bergen, Norway, ${ }^{2}$ Broegelmann Research Laboratory, Department \\ of Clinical Science, University of Bergen, Bergen, Norway, ${ }^{3}$ Swiss Institute of Bioinformatics, Lausanne, Switzerland, \\ ${ }^{4}$ Computational Biology Unit, Department of Informatics, University of Bergen, Bergen, Norway, ${ }^{5}$ Department of \\ Medicine, Haukeland University Hospital, Bergen, Norway
}

OPEN ACCESS

Edited by:

Anne Puel,

Institut national de la santé et de la recherche médicale, France

Reviewed by:

Michail Lionakis,

National Institute of Allergy and Infectious Diseases, United States Carolina Prando, Instituto Pelé Pequeno Príncipe, Brazil

*Correspondence: Anette S. B. Wolff anette.boe@uib.no

Specialty section: This article was submitted to Primary Immunodeficiencies, a section of the journal

Frontiers in Immunology

Received: 24 May 2017

Accepted: 17 August 2017 Published: 01 September 2017

Citation:

Bruserud Ø, Bratland E, Hellesen A, Delaleu N, Reikvam H, Oftedal BE and Wolff ASB (2017) Altered Immune Activation and IL-23 Signaling in Response to Candida albicans in Autoimmune Polyendocrine Syndrome Type 1.

Front. Immunol. 8:1074. doi: 10.3389/fimmu.2017.01074
Objective: Autoimmune polyendocrine syndrome type 1 (APS-1) is a rare, childhood onset disease caused by mutations in the autoimmune regulator (AIRE) gene. Chronic mucocutaneous candidiasis $(\mathrm{CMC})$ is one of the three major disease components and is, to date, mainly explained by the presence of neutralizing auto-antibodies against cytokines [interleukin (IL)-17A, IL-17F, and IL-22] from $\mathrm{T}$ helper 17 cells, which are critical for the protection against fungal infections. However, patients without current auto-antibodies also present CMC and we, therefore, hypothesized that other immune mechanisms contribute to CMC in APS-1.

Methods: Whole blood was stimulated with Candida albicans (C. albicans) in a standardized assay, and immune activation was investigated by analyzing 46 secreted immune mediators. Then, peripheral blood mononuclear cells were stimulated with curdlan, a Dectin-1 agonist and IL-23 inducer, and the IL-23p19 response in monocytes was analyzed by flow cytometry.

Results: We found an altered immune response in APS-1 patients compared with healthy controls. Patients fail to increase the essential ILs, such as IL-2, IL-17A, IL-22, and IL-23, when stimulating whole blood with $C$. albicans. A significantly altered IL-23p19 response was detected in patients' monocytes upon stimulation with curdlan.

Conclusion: APS-1 patients have an altered immune response to $C$. albicans including a dysregulation of IL-23p19 production in monocytes. This probably contributes to the selective susceptibility to CMC found in the majority of patients.

Keywords: autoimmune polyendocrine syndrome type 1, chronic mucocutaneous candidiasis, monocytes, IL-17, IL-22, IL-23

\section{INTRODUCTION}

Autoimmune polyendocrine syndrome type 1 (APS-1) or autoimmune polyendocrinopathycandidiasis-ectodermal dystrophy (OMIM 240300) is clinically defined by the presence of two of the three major disease components primary adrenal insufficiency, hypoparathyroidism (HP), and chronic mucocutaneous candidiasis (CMC) (1). However, the phenotypic expression of the 
syndrome is highly variable and includes many minor disease components (2). All patients present auto-antibodies against autoantigens expressed in the affected tissue and/or against immune mediators (3-5). The autoimmune regulator (AIRE) gene is the disease-causing gene (6-8). AIRE acts as a transcription factor and is almost exclusively expressed in the thymus (9), where it orchestrates the process of negative selection of self-reactive $\mathrm{T}$ cells and contributes to the development of regulatory T cells (Tregs) $(10,11)$.

Candida albicans (C. albicans) is an opportunistic yeast, colonizing the skin and mucosa of most healthy individuals without causing tissue damage or disease (12). However, it may cause superficial mucocutaneous or systemic infections; often in individuals with impaired immune functions. In APS-1, CMC caused by $C$. albicans is the most common and earliest main manifestation (13) and is reported in $75-100 \%$ of patients $(1,4$, 14-17). The clinical course varies from periodic to chronic and usually affects the oral mucosa as angular chelitis, or the whole mouth with hypertrophic and/or atrophic lesions $(1,2,13)$. Skin, nails, and genital mucosa in females may also be affected. Susceptibility to candidiasis maps to mucosal, not systemic, disease in APS-1 (1).

Interleukin (IL)-23 is required for differentiation, function, and maintenance of $\mathrm{T}$ helper 17 (Th17) cells, and this signaling axis plays a central role in host defense against cutaneous candidiasis (18). In APS-1, neutralizing autoantibodies against the Th17 cytokines, IL-17A, IL-17F, and IL-22, are suggested to explain the impairment in mucosal immunity $(19,20)$. Noteworthy, patients without autoantibodies also present CMC (4), and therefore, it remains disputable whether the Th17 cytokine-neutralizing autoantibodies are sufficient to precipitate CMC. To gain a better understanding of the molecular mechanism of CMC in APS-1, we investigated the immune activation in response to C. albicans in both whole blood and monocytes of patients finding a generally altered immune activation including a dysregulation in the IL-23/Th17 pathway.

\section{MATERIALS AND METHODS}

\section{Patients and Clinical Data}

Patients $(n=18)$ were included from our National Registry of Organ Specific Autoimmune Diseases and were previously described in the Norwegian cohort $(4,21,22)$. All fulfilled the diagnostic criteria of APS-1 (2). Patients received appropriate hormone replacement therapy of endocrine deficiencies at physiological doses. In HP, normal levels of calcium were maintained with oral administration of cholecalciferol and calcium. However, these treatments should not have significant immunomodulatory effects. None of the patients or healthy controls was pregnant, had acute infections, or received vaccinations at the time of sampling. An overview of the patients' data is given in Table 1. Samples from all patients were not available for all experiments. Healthy age and gender matched controls $(n=31)$ were recruited from the local blood bank at Haukeland University Hospital. All participants gave informed and written consent, and the study was approved by The Regional Committee for Medical and Health Research Ethics for Western Norway.

\section{Measurement of Immune Mediators}

In vitro production of immune mediators in response to C. albicans was characterized using the TrueCulture assay system (Myriad, RBM, USA). One milliliter of whole blood was taken from APS-1 patients $(n=11)$ and age- and sex-matched healthy controls $(n=13)$ into TrueCulture collection and culture tubes (Myriad, RBM) that contained either the supplied media (baseline response) or media supplemented with $C$. albicans (ATCC 10231; Myriad, RBM). Following a $48 \mathrm{~h}$ activation period at $37^{\circ} \mathrm{C}$, the supernatants were frozen and sent to Myriad RBM's testing laboratory where 46 unique analytes or biomarkers of immune activation were assessed using the multiplex immunoassay Human InflammationMAP 1.0 panel (Myriad, RBM). Mediators of special interests (IL-17A, IL-17F, IL-22, and IL-23p19) were also assayed with enzyme-linked immunosorbent assay (ELISA) (R\&D Systems, UK) for all patients included in this experiment $(n=11)$ and an extended group of healthy controls $(n=19)$. These ELISAs were done on supernatants from the corresponding TrueCulture tube. Standard sandwich ELISA was performed on sera from all patients $(n=18)$ searching for auto-antibodies against IL-23 (PeproTech, USA).

\section{Isolation and Culture of Cells}

Peripheral blood mononuclear cells from APS-1 patients $(n=6)$ and healthy controls $(n=12)$ were isolated from heparinized blood by Ficoll-Paque PLUS (GE Healthcare) density gradient centrifugation and stored at $-150^{\circ} \mathrm{C}$. Cryopreserved peripheral blood mononuclear cells (PBMCs) were used in all cell experiments. PBMCs $\left(10^{6}\right.$ cells $\left./ \mathrm{mL}\right)$ were cultured overnight in RPMI-1640 medium (Lonza) supplemented with 10\% human AB serum (Sigma, USA) and $1 \%$ penicillin-streptomycin (Sigma) at $37^{\circ} \mathrm{C}$ with $5 \% \mathrm{CO}_{2}$. For the immune stimulation and activation of monocytes, $10 \mu \mathrm{g} / \mathrm{mL}$ of the Dectin-1 agonist beta-1,3-glucan (Curdlan AL, InvivoGen, USA) was added to the cell cultures. Lipopolysaccharide from Salmonella abortus equi (SigmaAldrich) in a concentration of $1 \mu \mathrm{g} / \mathrm{mL}$ was used as a non-Candida positive control for monocyte activation. The protein transport inhibitor Brefeldin A (BioLegend, USA) was added at $1 \mu \mathrm{g} / \mathrm{mL}$ 90-120 min after the start of incubation.

\section{Flow Cytometry}

After the incubation period, cells were washed with $2 \mathrm{~mL}$ buffer [phosphate-buffered saline (Sigma) containing 5\% fetal bovine serum (Life technologies)] and centrifuged at $350 \times g$ for $5 \mathrm{~min}$. Cell surface staining of monocytes was done in $0.1 \mathrm{~mL}$ buffer for $30 \mathrm{~min}$ on ice with fluorescein isothiocyanate-conjugated antibody to human CD14 (clone HCD14, BioLegend) at a dilution of 1:20. Cells were then washed and fixed in $0.5 \mathrm{~mL} /$ tube Fixation Buffer (BioLegend) in the dark for $20 \mathrm{~min}$ at room temperature before centrifugation at $350 \times g$ for $5 \mathrm{~min}$ and then washed again. The fixed cells were re-suspended in $0.1 \mathrm{~mL}$ Intracellular Staining Perm Wash Buffer (BioLegend) and stained with $10 \mu \mathrm{L}$ phycoerythrin-conjugated antibody to human IL-23p19 (clone \#727753; R\&D Systems) in the dark for $20 \mathrm{~min}$ at room 
TABLE 1 | Characterization of the autoimmune polyendocrine syndrome type 1 (APS-1) patients.

\begin{tabular}{|c|c|c|c|c|c|c|c|c|c|}
\hline $\begin{array}{l}\text { Patient } \\
\text { number }\end{array}$ & $\begin{array}{l}\text { Family } \\
\text { number }\end{array}$ & Sex & $\begin{array}{l}\text { Year of } \\
\text { birth } \\
\text { (YoB) }\end{array}$ & $\begin{array}{l}\text { Age of } \\
\text { onset }\end{array}$ & Classic triad & $\begin{array}{l}\text { Other } \\
\text { manifestations }\end{array}$ & $\begin{array}{l}\text { Autoimmune regulator } \\
\text { (AIRE) mutations }\end{array}$ & $\begin{array}{l}\text { IFN } \omega \text { auto- } \\
\text { antibodies }\end{array}$ & Other auto-antibodies \\
\hline 1 & I & $\mathrm{M}$ & 1995 & 3 & $\begin{array}{l}\mathrm{CMC}(3), \operatorname{HP}(4) \\
\operatorname{PAI}(12)\end{array}$ & $\begin{array}{l}\operatorname{Al}(4), \operatorname{TIN}(15) \\
\operatorname{AT}(16), E\end{array}$ & c.967_979del13/c.769C>T & Positive & $210 \mathrm{H}, \mathrm{IL}-17, \mathrm{IL}-22, \mathrm{TGM} 4$ \\
\hline 2 & I & M & 1992 & 2 & $\mathrm{CMC}(2), \mathrm{HP}(4)$ & $\mathrm{K}(11), \mathrm{M}(15), \mathrm{E}$ & c.967_979del13/c.769C>T & Positive & $\begin{array}{l}\text { AADC, GAD65, IL-17, IL-22, } \\
\text { TGM4, TH }\end{array}$ \\
\hline 3 & $\|$ & $\mathrm{F}$ & 1958 & 5 & $\begin{array}{l}\mathrm{CMC}(5), \operatorname{HP}(9) \\
\operatorname{PAl}(14)\end{array}$ & $\begin{array}{l}\mathrm{G}(18), \mathrm{AS}(43) \\
\operatorname{TIN}(47), \mathrm{E}(53)\end{array}$ & c.967_979del13/large del & Positive & $\begin{array}{l}21 \mathrm{OH}, 17 \mathrm{OH}, \mathrm{IL}-22, \mathrm{MAGEB} 2 \\
\text { NALP5, SCC, TH }\end{array}$ \\
\hline 4 & $\|$ & $\mathrm{F}$ & 2002 & 7 & $\begin{array}{l}\operatorname{PAI}(7), \mathrm{HP}(10) \\
\mathrm{CMC}\end{array}$ & $\mathrm{E}, \mathrm{M}$ & $\begin{array}{l}\text { c.967_979del13/ } \\
\text { c.967_979del13 }\end{array}$ & Positive & $\begin{array}{l}\text { 21OH, 17OH, AADC, GAD65, IL-22, } \\
\text { MAGEB2, NALP5, SCC, TH, TPH1 }\end{array}$ \\
\hline 5 & III & $\mathrm{M}$ & 1948 & 7 & $\begin{array}{l}\operatorname{CMC}(7), \operatorname{HP}(9) \\
\operatorname{PAl}(16)\end{array}$ & $\begin{array}{l}\mathrm{V}(17), \mathrm{Al}(21) \\
\mathrm{B} 12(63), \mathrm{E}\end{array}$ & c. $769 \mathrm{C}>\mathrm{T} / \mathrm{c} .769 \mathrm{C}>\mathrm{T}$ & Positive & $\begin{array}{l}\text { 21OH, AADC, IL-17, IL-22 MAGEB2, } \\
\text { SCC, SOX10, TGM4 }\end{array}$ \\
\hline 6 & IV & $\mathrm{F}$ & 1960 & 9 & $\mathrm{HP}(9), \mathrm{CMC}$ & $\begin{array}{l}\mathrm{Al}(6), \mathrm{G}(17) \\
\text { AT, E, N }\end{array}$ & c.22C>T/c.290T>C & Positive & NALP5, PCA \\
\hline 7 & V & $\mathrm{M}$ & 1970 & 12 & $\operatorname{PAl}(12), \mathrm{CMC}(42)$ & $\mathrm{E}$ & $\begin{array}{l}\text { c.967_979del13/ } \\
\text { c.967_979del13 }\end{array}$ & Positive & $21 \mathrm{OH}, \mathrm{GAD65}, \mathrm{IL}-22, \mathrm{SCC}$ \\
\hline 8 & VI & $\mathrm{F}$ & 1974 & 23 & $\operatorname{PAl}(23), \mathrm{CMC}(23)$ & $\mathrm{E}$ & c. $879+1 G>A / c .879+1 G>A$ & Positive & $210 \mathrm{H}, 17 \mathrm{OH}, \mathrm{NALP} 5$ \\
\hline 9 & $\mathrm{VI}$ & $\mathrm{M}$ & 1959 & 43 & $\mathrm{HP}(43), \mathrm{CMC}$ & $\begin{array}{l}V(15), \operatorname{DM}(32) \\
E(49), A T(51)\end{array}$ & c. $879+1 G>A / c .879+1 G>A$ & Positive & $\begin{array}{l}21 \mathrm{OH}, 17 \mathrm{OH}, \mathrm{AADC}, \mathrm{GAD} 65 \\
\text { NALP5, TH, TPH1 }\end{array}$ \\
\hline 10 & VII & M & 1964 & 14 & $\mathrm{HP}(14), \mathrm{CMC}(22)$ & $\begin{array}{l}\mathrm{DM}(23), \mathrm{K}(25) \\
\mathrm{N}(25), \mathrm{V}(41) \\
\mathrm{Al}(41), \mathrm{E}\end{array}$ & c.769C>T/c.1249dupC & Positive & $\begin{array}{l}\text { AADC, GAD65, IL-22, PCA, } \\
\text { PDILT, TGM4, TH, TPH1 }\end{array}$ \\
\hline 11 & VII & $\mathrm{M}$ & 1963 & $\mathrm{nk}$ & CMC? & $\mathrm{E}$ & c.769C>T/c.1249dupC & Positive & AADC, IL-22, SOX10, TGM4 \\
\hline 12 & VIII & $\mathrm{F}$ & 1988 & 3 & $\mathrm{HP}(3)$ & AT(24), E, M & $\begin{array}{l}\text { c.967_979del13/ } \\
\text { c.967_979del13 }\end{array}$ & Positive & NALP5 \\
\hline 13 & IX & $\mathrm{F}$ & 1987 & 2 & $\mathrm{CMC}(2), \mathrm{HP}(15)$ & $E(24), A l, E$ & $\begin{array}{l}\text { c.1163_1164insA } \\
\text { c.1249_1950dupC }\end{array}$ & Positive & $\begin{array}{l}21 \mathrm{OH}, \text { AADC, IL-17, IL-22, } \\
\text { MAGEB2, NALP5, SOX10 }\end{array}$ \\
\hline 14 & $x$ & $\mathrm{~F}$ & 1971 & 5 & $\mathrm{HP}(5)$ & $\begin{array}{l}\mathrm{G}(19), \mathrm{B} 12(35) \\
M(39), \mathrm{E}\end{array}$ & c.934G $>$ A/not found & Positive & NALP5, AADC, GAD, PCA \\
\hline 15 & $X I$ & $\mathrm{~F}$ & 1976 & 4 & $\mathrm{HP}(4), \mathrm{C}$ & $\begin{array}{l}E(14), \operatorname{AT}(20) \\
V(25)\end{array}$ & $\begin{array}{l}\text { c.967-979del13/c.967- } \\
\text { 979del13 }\end{array}$ & Positive & $\begin{array}{l}\text { 21OH, 17OH, NALP5, TH, TPH, } \\
\text { AADC, GAD, SCC, MAGEB2, } \\
\text { SOX10, PDILT, IL-22 }\end{array}$ \\
\hline 16 & $X I$ & M & 1980 & 9 & $\begin{array}{l}\mathrm{HP}(9), \operatorname{PAl}(12) \\
\mathrm{C}(16)\end{array}$ & $E$ & $\begin{array}{l}\text { c.967-979del13/c.967- } \\
\text { 979del13 }\end{array}$ & Positive & $\begin{array}{l}210 H, \text { SCC, TH, AADC, GAD, } \\
\text { NALP5, TGM4, IL-17, IL-22 }\end{array}$ \\
\hline 17 & $X I I$ & $\mathrm{M}$ & 1958 & $\begin{array}{c}\text { Not } \\
\text { known }\end{array}$ & PAI(55), HP, C & Al, AS, E & $\begin{array}{l}\text { c.967-979del13/c.967- } \\
\text { 979del13 }\end{array}$ & Positive & GAD, TPH, MAGEB2, IL-17, IL-22 \\
\hline 18 & $X I I I$ & $\mathrm{~F}$ & 1982 & 5 & $\mathrm{CMC}(3)$ & $\begin{array}{l}V(15), P A(13) \\
E, M\end{array}$ & c.967-976del13/c.977C>T & Positive & $\begin{array}{l}\text { AADC, GAD65, IL-22, PCA, } \\
\text { PDILT, TPH1 }\end{array}$ \\
\hline
\end{tabular}

Patient number, family, sex (M, male; F, female), YoB, clinical manifestations, AIRE mutations and auto-antibodies in APS-1 patients. The age of debut denotes the age at which the first APS-1 main component appeared. The age at diagnosis is written in parentheses.

210H, 21-hydroxylase; 17OH, 17- $\alpha$-hydroxylase; AADC, aromatic L-amino acid decarboxylase; Al, alopecia; AS, asplenism; AT, autoimmune thyroiditis; CMC, candidiasis;

DM, diabetes mellitus; E, enamel hypoplasia; G, hypogonadism; GAD65, glutamic acid decarboxylase 65-kDA isoform; HP, hypoparathyroidism; IFN心, interferon-omega; IL-17, interleukin-17; IL-22, interleukin-22; K, keratoconjunctivitis; M, malabsorption; MAGEB2, melanoma antigen B2; N, nail hypotrophy; NALP5, NACHT leucine-rich-repeat protein 5; PA, pernicious anemia; PAl, primary adrenocortical insuffiency; PCA, parietal cell antigen; PDILT, protein disulfide isomerase-like testis expressed; SCC, side-cleavage enzyme; SOX10, sex-determining region Y-box 10; TGM4, transglutaminase 4; TIN, nephritis; TH, tyrosine hydroxylase; TPH, tryptophan hydroxylase; V, vitiligo.

temperature. Finally, another washing step was done before the fixed and stained cells were re-suspended in $0.3 \mathrm{~mL}$ buffer. Cells were analyzed on a BD FACS Accuri C6 flow cytometer. Individual populations were gated according to forward scatter (FSC), side scatter (SSC), and specific markers, and the data were subsequently analyzed with FlowJo X software.

\section{Statistical and Bioinformatical Analyses}

Paired $t$-tests were used analyzing paired data, and the MannWhitney $U$ test was used when comparing groups. The level of significance was defined to a $P$ value less than 0.05 . Statistical analyses were performed using IBM SPSS Statistics 23 or Prism 7 (Graph Pad Software, Inc., San Diego, CA, USA). Hierarchical cluster analyses were performed using the J-Express (MolMine AS, Bergen, Norway) (23), and the alterations analyzed were standardized after ratio after/before stimulation and $\log (2)$ transformed before unsupervised hierarchical clustering with Squared Euclidean distance measure with weighted average linkage was performed (23). Functional annotation and generation of the basic framework of the network displayed in Figure S1 in Supplementary Material were computed using ClueGO 2.3.3 (24) within the Cytoscape 3.4.0 suite (25). Proteins that in APS-1 patients failed to be up-regulated in response to $C$. albicans $(P>0.05)$ while found to be significantly increased in healthy controls upon $C$. albicans exposure $(P<0.05)$ were entered as group 1. Group 2 includes SERPINA1 and GC, which were found significantly down-regulated in APS-1 patients but were unchanged in healthy subjects when responding to C. albicans stimulation. These two groups were interrogated regarding their associations with a priori-defined biological terms comprised in the complete biological process gene ontology (GO) (GO:0008150; 23.02.2017). The analysis settings were (i) hits 
required to map a $\mathrm{GO}$ term $\geq 1$, (ii) percentage of a term covered by proteins reliably detected by the MAPs $\geq 4 \%$, and (iii) GO term fusion and GO term grouping was applied based on a kappa score of 0.4 (similarity measure between the GO terms). For each group of terms, the GO term accommodating the largest number of proteins was selected as its leading term. All other settings were used as per default.

\section{RESULTS}

In the TrueCulture assay, a total of 46 single mediators were analyzed in supernatants after the activation period of $48 \mathrm{~h}$. Table 2 gives an overview of all mediators analyzed, the response to C. albicans stimuli in patients and healthy controls, and $P$ values for paired analyses within each group.

TABLE 2 | Change of different immune mediators in response to Candida albicans in patients and controls.

\begin{tabular}{|c|c|c|c|c|}
\hline \multirow[t]{2}{*}{ Mediator } & \multicolumn{2}{|c|}{$\begin{array}{l}\text { Autoimmune polyendocrine } \\
\text { syndrome type } 1\end{array}$} & \multicolumn{2}{|c|}{ Controls } \\
\hline & $\begin{array}{l}\text { Response to } \\
\text { C. albicans }\end{array}$ & $P$ value & $\begin{array}{l}\text { Response to } \\
\text { C. albicans }\end{array}$ & $P$ value \\
\hline \multicolumn{5}{|c|}{ Interleukins } \\
\hline $\mathrm{IL}-1 \mathrm{~A}$ & $\uparrow$ & 0.001 & $\uparrow$ & 0.001 \\
\hline IL-1B & $\uparrow$ & 0.001 & $\uparrow$ & $<0.001$ \\
\hline IL-2 & $\rightarrow$ & Ns (0.115) & $\uparrow$ & 0.001 \\
\hline IL-3 & $\mathrm{Nd}$ & - & $\mathrm{Nd}$ & - \\
\hline IL-4 & $\uparrow$ & $<0.001$ & $\uparrow$ & $<0.001$ \\
\hline IL-5 & $\mathrm{Nd}$ & - & $\mathrm{Nd}$ & - \\
\hline IL-6 & $\uparrow$ & 0.014 & $\uparrow$ & 0.002 \\
\hline IL-7 & $\uparrow$ & 0.001 & $\uparrow$ & 0.037 \\
\hline IL-10 & $\uparrow$ & 0.008 & $\uparrow$ & 0.003 \\
\hline IL-12p40 & $\uparrow$ & 0.020 & $\uparrow$ & $<0.001$ \\
\hline IL-12p70 & $\mathrm{Nd}$ & - & $\mathrm{Nd}$ & - \\
\hline IL-15 & $\mathrm{Nd}$ & - & $\mathrm{Nd}$ & - \\
\hline IL-17A & $\rightarrow$ & Ns (0.115) & $\uparrow$ & $<0.001$ \\
\hline IL-18 & $\uparrow$ & $<0.001$ & $\uparrow$ & $<0.001$ \\
\hline IL-22 ${ }^{\mathrm{a}}$ & $\rightarrow$ & Ns $(0.240)$ & $\uparrow$ & 0.002 \\
\hline IL-23 & $\rightarrow$ & Ns (0.342) & $\uparrow$ & 0.035 \\
\hline \multicolumn{5}{|c|}{ Growth factors } \\
\hline BDNF & $\rightarrow$ & Ns (0.463) & $\rightarrow$ & Ns (0.203) \\
\hline CSF2 & $\uparrow$ & 0.007 & $\uparrow$ & 0.002 \\
\hline VEGFA & $\uparrow$ & 0.001 & $\uparrow$ & $<0.001$ \\
\hline \multicolumn{5}{|c|}{ Chemokines } \\
\hline CCL2 & $\uparrow$ & 0.002 & $\uparrow$ & $<0.001$ \\
\hline CCL3 & $\uparrow$ & 0.001 & $\uparrow$ & $<0.001$ \\
\hline CCL4 & $\uparrow$ & $<0.001$ & $\uparrow$ & $<0.001$ \\
\hline CCL5 & $\rightarrow$ & Ns $(0.514)$ & $\rightarrow$ & Ns (0.072) \\
\hline CCL11 & $\downarrow$ & 0.014 & $\downarrow$ & 0.004 \\
\hline CXCL8 & $\uparrow$ & $<0.001$ & $\uparrow$ & $<0.001$ \\
\hline \multicolumn{5}{|c|}{ Immunomodulatory cytokines } \\
\hline INFg & $\uparrow$ & 0.003 & $\uparrow$ & 0.014 \\
\hline LTA & $\uparrow$ & $<0.001$ & $\uparrow$ & $<0.001$ \\
\hline TNF & $\uparrow$ & 0.002 & $\uparrow$ & $<0.001$ \\
\hline \multicolumn{5}{|c|}{ Adhesion molecules } \\
\hline ICAM1 & $\rightarrow$ & Ns (0.582) & $\rightarrow$ & Ns (0.377) \\
\hline VCAM1 & $\rightarrow$ & Ns $(0.401)$ & $\rightarrow$ & Ns (0.546) \\
\hline \multicolumn{5}{|c|}{ Matrix metalloproteases } \\
\hline MMP3 & $\rightarrow$ & Ns $(0.740)$ & $\rightarrow$ & Ns (0.247) \\
\hline MMP9 & $\uparrow$ & 0.003 & $\uparrow$ & 0.004 \\
\hline
\end{tabular}

TABLE 2 | Continued

\begin{tabular}{|c|c|c|c|c|}
\hline \multirow[t]{2}{*}{ Mediator } & \multicolumn{2}{|c|}{$\begin{array}{l}\text { Autoimmune polyendocrine } \\
\text { syndrome type } 1\end{array}$} & \multicolumn{2}{|c|}{ Controls } \\
\hline & $\begin{array}{l}\text { Response to } \\
\text { C. albicans }\end{array}$ & $P$ value & $\begin{array}{l}\text { Response to } \\
\text { C. albicans }\end{array}$ & $P$ value \\
\hline \multicolumn{5}{|c|}{ Coagulation factors } \\
\hline C3 & $\rightarrow$ & Ns $(0.661)$ & $\uparrow$ & 0.030 \\
\hline F7 & $\rightarrow$ & Ns (0.060) & $\rightarrow$ & Ns (0.101) \\
\hline FGA & $\rightarrow$ & Ns $(0.450)$ & $\uparrow$ & 0.011 \\
\hline VWF & $\rightarrow$ & Ns (0.807) & $\rightarrow$ & Ns (0.464) \\
\hline \multicolumn{5}{|c|}{ Serum proteins } \\
\hline B2M & $\rightarrow$ & Ns (0.637) & $\uparrow$ & 0.024 \\
\hline FTL & $\uparrow$ & 0.002 & $\uparrow$ & $<0.001$ \\
\hline $\mathrm{HP}$ & $\rightarrow$ & Ns (0.562) & $\rightarrow$ & Ns (0.967) \\
\hline \multicolumn{5}{|c|}{ Traditional markers } \\
\hline CRP & $\rightarrow$ & 0.124 & $\rightarrow$ & 0.725 \\
\hline \multicolumn{5}{|l|}{ Others } \\
\hline GC & $\downarrow$ & 0.037 & $\rightarrow$ & Ns (0.974) \\
\hline SERPINA1 & $\downarrow$ & 0.028 & $\rightarrow$ & Ns (0.683) \\
\hline IL1RN & $\uparrow$ & $<0.001$ & $\uparrow$ & $<0.001$ \\
\hline KITL & $\uparrow$ & 0.002 & $\uparrow$ & $<0.001$ \\
\hline TIMP1 & $\uparrow$ & 0.017 & $\uparrow$ & $<0.001$ \\
\hline TNFRSF1B & $\uparrow$ & $<0.001$ & $\uparrow$ & $<0.001$ \\
\hline
\end{tabular}

The table gives the mediators analyzed in the TrueCulture system and the response to C. albicans in both patients and healthy controls. T-test for paired data was used for statistical comparison. $\uparrow$ indicates a significant up-regulation, $\downarrow$ indicates a significant down-regulation, and $\rightarrow$ indicates no significant change in the mediator concentration. Mediators with a significant different response in patients and controls are marked bold. $\mathrm{Nd}$, not detectable; Ns, not significant.

alL-22 was not included in the TrueCulture system but analyzed with enzyme-linked immunosorbent assay.

\section{Most Chemokines, Interleukins, and Immune Regulatory Cytokines Increase in Response to C. albicans in Both Patients and Healthy Controls}

Both APS-1 patients and healthy controls had a significant increase in levels of several mediators in response to C. albicans. A significant up-regulation in APS-1 and controls was found in the analyzed $\gamma$-chemokines CCL2, CCL3, and CCL4, the $\alpha$-chemokine CXCL8, and the interleukins IL-1 $\beta$, IL-4, IL-6, IL-7, IL-10, IL-12p40, and IL-18 (Table 2). Similarly, IL-1RN, the three immune regulatory cytokines LTA, TNF, and IFN $\gamma$ and the growth factors CSF2 and VEGF were found to be significantly increased in both groups. Notably, when comparing the responses in the two groups, significant differences were found for 16 mediators (Table S1 in Supplementary Material; Figure 1). CCL11 was the only mediator analyzed, which significantly decreased in response to C. albicans in both groups. Finally, a total of 11 mediators analyzed remained unchanged in both groups after stimulation of whole blood by C. albicans (Table 2).

\section{APS-1 Patients Have an Altered Th17 Cytokine Response to C. albicans Compared to Healthy Controls}

A subset of related mediators failed to increase in response to C. albicans in APS-1 patients compared to healthy controls. Interestingly, patients fail to increase the essential interleukins 


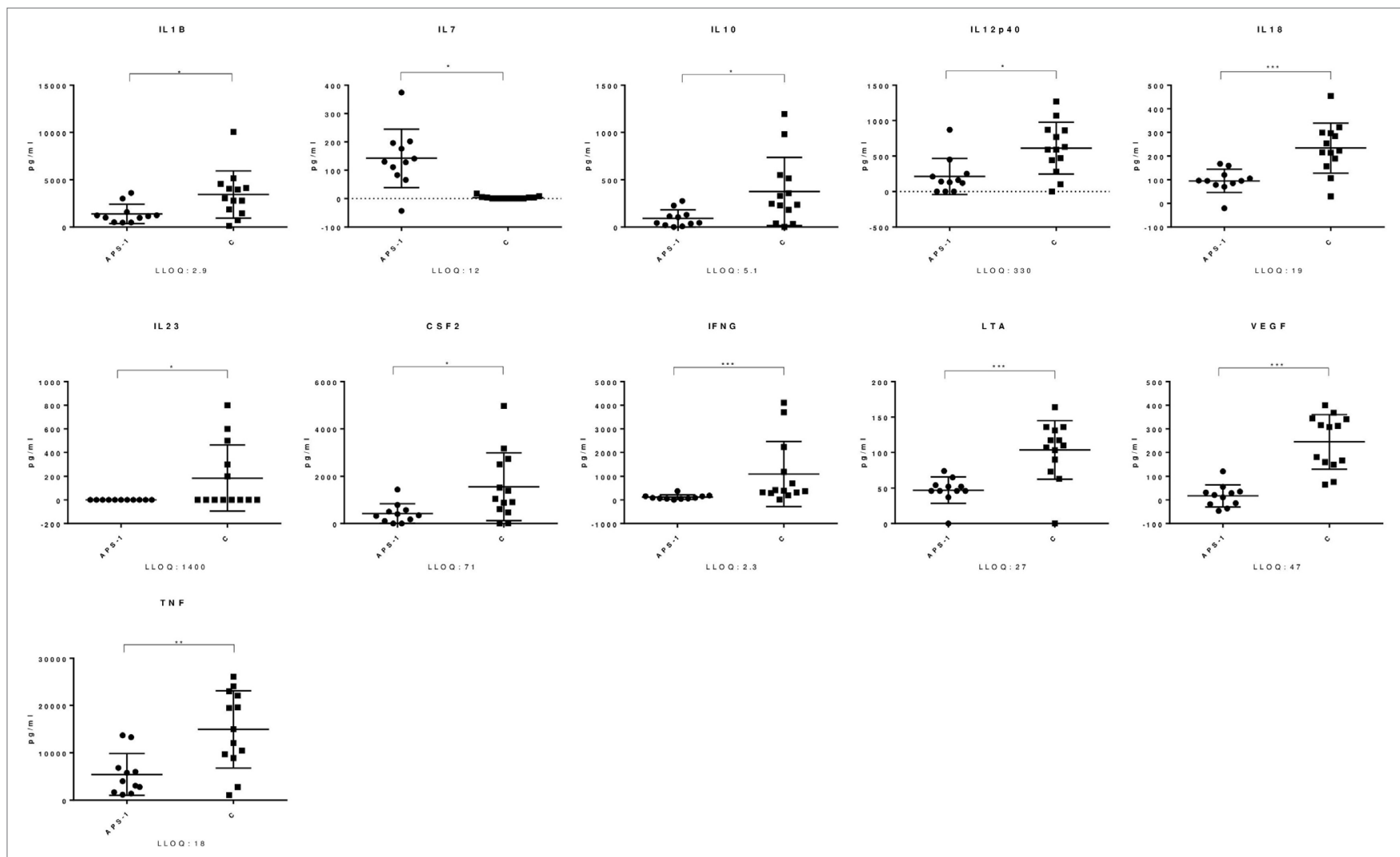

FIGURE 1 | Mediators with significant different response in Autoimmune polyendocrine syndrome type 1 (APS-1) and controls. The figure shows selected mediators from the TrueCulture assay and significant differences were found comparing APS-1 and controls (C). The lines indicate the mean with standard deviation. Concentrations are given at the $y$-axis. $L L O Q$, lower limit of quantitation. ${ }^{\star} P \leq 0.05$; ${ }^{\star \star} P \leq 0.01$; ${ }^{\star \star \star} P \leq 0.001$.

IL-17A, IL-22, and IL-23 (Table 2). IL-22 was not included in the TrueCulture assay and, therefore, analyzed with standard ELISA on the TrueCulture supernatants, and IL-17A and IL-23 were analyzed in both assays with comparable results. In controls, the strength of IL-22 correlated with IL-17A (correlation $0.869, P=0.001$ ) and IL-23 correlated with IL-17F (correlation $0.612, P=0.026$ ). These correlations could not be observed in patients. No APS-1 patients or controls had auto-antibodies against IL-23 assayed by sandwich ELISA. The other mediators revealing a different response in patients were $\beta 2$-microglobulin (B2M), C3, and FGA, whereas GC and SERPINA1 remained unchanged in healthy controls and decreased significantly in APS-1 patients. All mediators with a significant different response comparing patients and controls are highlighted in Table 2.

\section{Unsupervised Hierarchical Clustering Based on Changes in Immune Mediators and Functional Annotation of the Protein Profile Characterizing the Altered Immune Response in APS-1 Patients}

We used the relative values of the measured levels of all mediators analyzed in the TrueCulture assay in an unsupervised hierarchical clustering analysis (Figure 2). Patients and controls were divided into two main clusters/subsets, and most patients were included in the left cluster (7 of 11) and most controls in the right cluster (9 of 13). However, no significant difference was found when comparing expected and observed frequencies using the Chi-square test $(P=0.107)$. Figure $S 1$ in Supplementary Material shows a protein:gene ontology- $(\mathrm{GO})$ term network, which identified four clusters of biological processes, each with its leading term, that most efficiently interconnect the nine proteins showing significantly different responses to $C$. albicans among patients and controls. Any regulatory relationships between the proteins, as per CluePedia v10.0, are displayed as well.

\section{Monocytes from APS-1 Patients Have an Impaired IL-23p19 Response When Stimulated with Curdlan}

We found comparable numbers of monocytes in unstimulated PBMCs from patients and controls (Table 3), and no significant difference in frequencies of IL-23p19+ cells was found comparing unstimulated cultures. Although not significant, patients seem to have a greater variability in both numbers of monocytes when gating on FSC/SSC and CD14 ${ }^{+}$monocytes (Table 3; Figure S2 in Supplementary Material). However, when comparing 


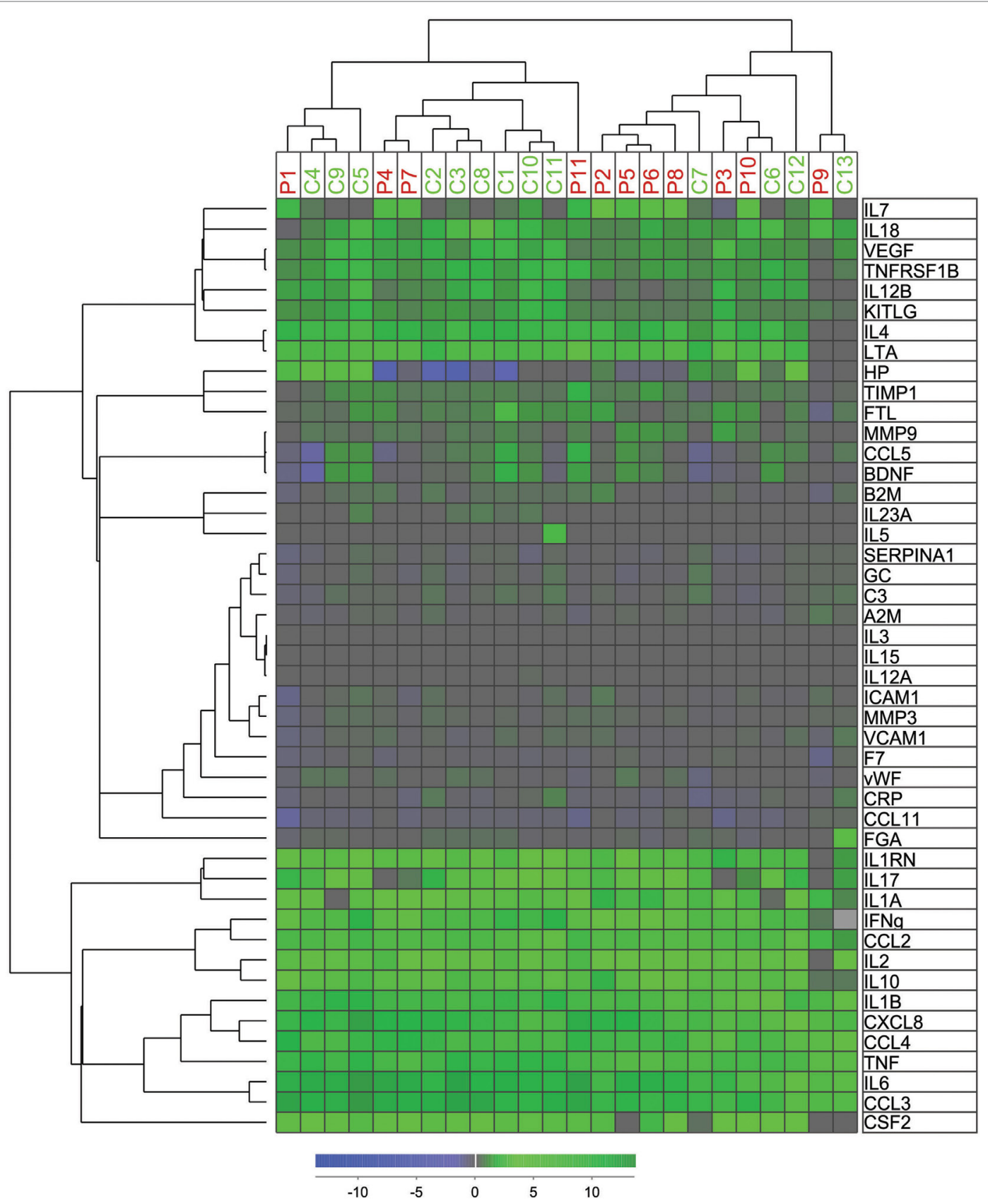

FIGURE 2 | Hierarchical cluster analyses of mediator alteration in control and patients. Unsupervised hierarchical cluster analyses and distance matrix analyses for 11 patients (red P1-P11) and 13 controls (green C1-C13) were performed. Concentrations of mediators were measured before and after intervention as previously described. The alterations were standardized after ratio after/before intervention and log(2) transformed before unsupervised hierarchical clustering with Squared Euclidean distance measure with weighted average linkage was performed, resulting in a heat map for visualization and interpretation. The mediator alteration profiles identified to main patients/control clusters and two main cytokine clusters.

unstimulated and stimulated monocytes, the levels of IL-23p19 were significantly increasing in controls, whereas this was not found in APS-1 (Figures 3A,B; Figure S2 in Supplementary Material). Moreover, healthy controls had a significant greater increase in total IL-23 $19^{+}$monocytes upon stimulation with curdlan (Figure 3C).

\section{DISCUSSION}

Chronic mucocutaneous candidiasis as a major clinical disease manifestation in APS-1 suggests immune defects in mechanisms crucial in fungal defense. The aims of the present study were to characterize APS-1 patients' immune activation in response to 
C. albicans and our findings clearly state that APS-1 patients have an altered immune activation compared to healthy controls. IL-23p19, which is required for the formation of Th17 cells, was found dysregulated both in whole blood and monocytes upon stimulation with C. albicans indicating its contribution to CMC in patients.

The overall differences detected in the immune mediators in APS-1 patients have relatively broad implications on the quality of the immune response against C. albicans (Figure $S 1$ in Supplementary Material). Importantly, with regard to immune responses against Candida, biological processes involving positive regulation of IL-17- and IL-23 production, as well as positive regulation of lymphocyte mediated immunity, were clearly impaired in patients. The significance of the other enriched biological processes impaired in patients, positive regulation of T-cell-mediated cytotoxicity, and immunoglobulin-mediated immune responses, respectively, is less obvious. However, a severely impaired general $\mathrm{CD}^{+} \mathrm{T}$-cell homeostasis has been previously reported in APS-1 patients (26). The importance of

TABLE 3 | Monocyte counts in autoimmune polyendocrine syndrome type 1 (APS-1) and controls.

\begin{tabular}{lccc}
\hline Cells & APS-1 & Controls & P value \\
\hline $\begin{array}{l}\text { Monocytes [forward } \\
\text { scatter (FSC)/side }\end{array}$ & $8.810(1.98-16.6)$ & $11.70(8.32-16.00)$ & Ns (0.0978) \\
scatter (SCC)] & & & \\
CD14+ monocytes & $64.9(29.0-86.90)$ & $79.45(67.10-87.80)$ & Ns (0.3355) \\
Interleukin (IL)-23p19+ & $0.33(0.00-1.69)$ & $1.00(0.078-1.73)$ & Ns (0.4796) \\
monocytes - 0 & & & Ns (0.0831) \\
IL-23p19+ monocytes & $0.75(0.00-2.32)$ & $1.655(0.28-3.33)$ & \\
- curdlan & & & \\
\hline
\end{tabular}

The table gives a comparison of percent monocytes in APS-1 and controls both when gated on FSC/SSC and the number of $\mathrm{CD}_{14}{ }^{+}$monocytes in the current monocyte gate. Numbers are given as median (and range). The Mann-Whitney $U$ test was used for the statistical comparison.

0 , baseline/unstimulated. Ns, not significant. humoral immunity against Candida is suggested to be relatively modest compared to cellular defense mechanisms (27). Still, the most important mediator in the biological process involving immunoglobulin mediated immune responses was the complement factor C3, which APS-1 patients failed to up-regulate in response to $C$. albicans. C3 plays several important roles during the early innate responses against Candida, through opsonization and subsequently recognition and phagocytosis by neutrophils and monocytes (28). Moreover, comparing the increase in immune mediators in response to C. albicans, significant differences between patients and controls were found for several mediators (IL-1 $\beta$, IL-10, IL-12p40, IL-18, and IL-23) involved in the crosstalk between innate immune cells and subsets of $\mathrm{T}$ cells. This indicates that several cellular mechanisms may be involved in altering the immune response in patients. NOD-like receptors are cytosolic proteins that are implicated in sensing fungi and, once activated, produce IL- $1 \beta$ and IL- 18 through the formation of inflammasomes (29), both of which were less up-regulated in patients compared to controls in response to Candida stimulation. IL-1 $\beta$ is crucial for the differentiation of Th17 cells and for the activation and recruitment of neutrophil granulocytes, while IL-18 is important for the induction of IFN $\gamma$ producing $\mathrm{T}$ helper 1 (Th1) cells. IL-10 is produced by almost all immune cells and its major role is to limit the extent of immune activation and retain homeostasis (30). IL-12 is a pro-inflammatory molecule primarily produced by professional antigen-presenting cells (31) and it activates natural killer cells and induces the differentiation of naïve CD4+ T lymphocytes to become Th 1 cells (31). Notably, the IL-12p40 chain of IL-12 can also form a dimer with p19 giving rise to IL-23 (32), which is required for Th17 differentiation, function and maintenance. Patients failed to increase IL-17A, IL-22, and IL-23, which are found critical for optimal host defense against cutaneous candidiasis (18) and fungal infections $(19,20)$. Previous studies have reported conflicting results about IL-17 production in APS-1 $(20,33)$,

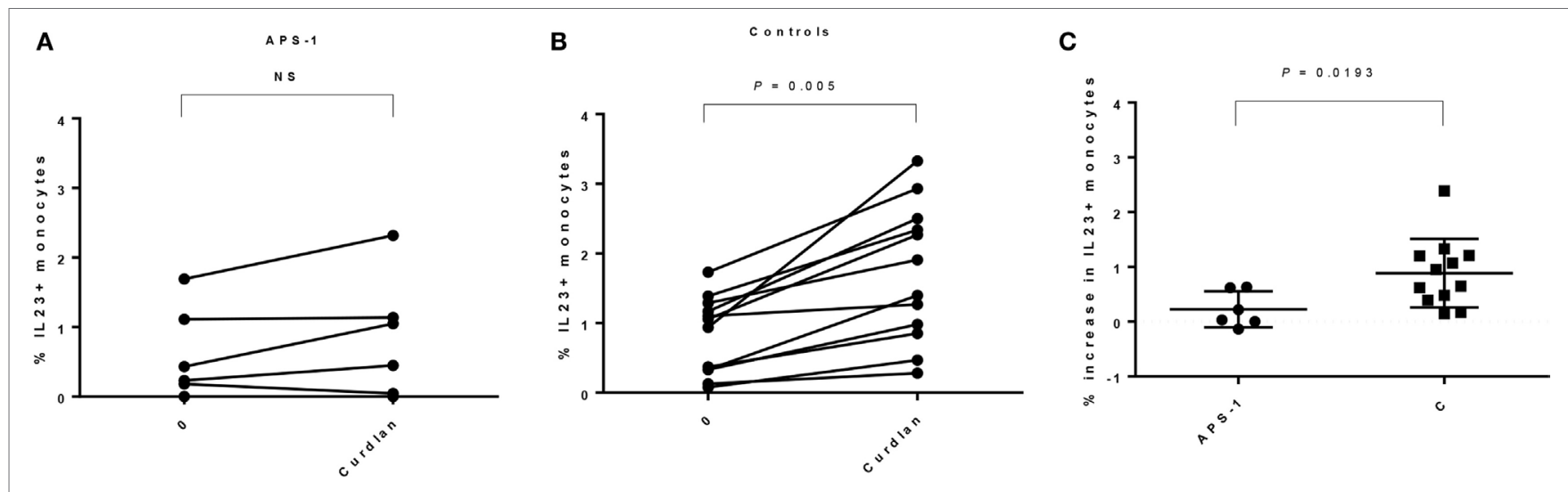

FIGURE 3 | Interleukin (IL)-23p19 responses found in monocytes in autoimmune polyendocrine syndrome type 1 (APS-1) patients and controls. The figure gives an overview of the IL-23p19 response found in monocytes in patients versus controls. (A) APS-1 patients; no significant increase in IL-23p19 was detected in monocytes. Numbers at the $Y$-axis gives the percentages of IL-23p19+ monocytes after stimulation with curdlan. (B) Controls; a significant increase in IL-23p19 was detected in monocytes. The numbers at the $Y$-axis give the percentages of IL-23p19+ monocytes after stimulation with curdlan. (C) Comparing the increase in IL-23p19+ monocytes found in APS-1 and controls at baseline and after curdlan stimulation. NS, not significant. 
but the finding of reduced IL-22 producing cells in APS-1 seems more consistent $(20,33,34)$. Finally, we also confirm a dysregulation of IL-7, which is previously described in a Finnish APS-1 cohort (26). Although a more comprehensive study of the system biology would generate an even better overview of the immune activation and biological pathways involved in the response to Candida in APS-1, our findings indicate an altered immune activation in APS-1 patients, which includes several immune mediators that play important roles in immune homeostasis and particularly in the host defense against fungi (Figure S1 in Supplementary Material).

Interleukin-23 and Th17 cytokines have been implicated in the pathogenesis of many autoimmune diseases (35-37), and we therefore found the total lack of IL-23 in APS-1 patients particularly interesting. IL-23 is secreted by activated monocytes and dendritic cells (38) and induces the differentiation of naïve T cells into Th17 cells and can promote the further expansion and maintenance of Th17 cells, and the production of Th17 cytokines via IL-23 receptor and STAT3 (38). In the literature, there is already conflicting information about IL-23 signaling in APS-1. Ryan and collaborators described monocyte-derived DCs from APS-1 patients to over-produce IL-2, INF $\gamma$, TNF- $\alpha$, and IL-13 and demonstrated both impairment in maturation and hyper activation in response to C. albicans (39). However, the IL-23 response was comparable to controls (39). Another study assessed Th17 responses of PBMCs to Candida and non-Candida species stimuli finding that PBMCs from APS-1 patients had a normal or increased IL-17 production and Th17 cell proliferation, although only in the absence of their own plasma, which had an inhibitory effect on both IL-17 production and Th17 cell proliferation (34). This study reported normal IL- 6 and IL- 23 responses in APS-1 patients. Furthermore, expression levels of all pattern recognition receptors (PRRs) involved in anti-candida responses, levels of plasmacytoid and myeloid DCs, and monocyte toll-like receptor (TLR)-2/TLR-6 expression are described similar in APS-1 and controls (40). Finally, we have previously reported reduced numbers of CCR $6^{+}$CXCR $3^{+}$ $\mathrm{T}$ helper cells, CD16 $6^{+}$monocytes, and Tregs in patients with APS-1 (41). These previous studies have investigated IL-23 from DCs and PBMCs in APS-1 $(34,39,40)$, but less information about monocytes exists. We report comparable numbers of monocytes in both patients and controls and similar levels of IL-23p19 in unstimulated monocytes. Interestingly, monocytes from patients fail to increase IL-23p19 production both when comparing the steady-state levels and stimulated levels within each group and when comparing the total increase between the groups. The reason for the discrepancy in IL-23 production in the studies mention above and our current findings could be due to differences in cell types studied (PBMCs, DCs, monocytes, and whole blood), or that PRRs activate differently to particular Candida strains. These important aspects need to be further investigated.

Furthermore, there are conflicting information about the clinical relevance of monocyte-specific IL-23 signaling and CMC. Patients with autosomal recessive IL-12RB1 or IL-12p40 deficiency suffer from CMC and, therefore, indicate that impairment of IL-23 signaling can be the molecular pathogenesis of CMC $(42,43)$. On the other hand, CMC is not well described in patients with GATA2 deficiency, which severely impairs monocytes (44). Our findings suggest a monocyte-specific IL-23 deficiency in APS-1 patients, which resonates well with a previously published study reporting an extrathymic role of AIRE in monocytes (45). Specifically, that study described how AIRE interacts with CARD9, SYK, and Dectin-1 in healthy monocytes and thus plays a major role in activation of the Dectin-1 pathway by stimulation with curdlan. Consequently, PBMCs from AIRE-deficient APS-1 patients produced significantly less TNF in response to curdlan stimulation compared to healthy controls. Noteworthy, the expression and biological role of the AIRE protein in peripheral blood cells are controversial $(46,47)$, and the interpretation of our data in this context should be approached with caution until the expression of AIRE in monocytes has been further verified. Based on the above, a general impairment in immune activation and an altered monocyte response probably contribute to CMC found in APS-1 and is likely to involve the Dectin-1 pathway.

Auto-antibodies play a key role in CMC in APS-1, and auto-antibodies against IL-6, IL-17A, IL-17F, IL-22, and IFN $\omega$ are previously described $(19,20,48)$. We searched for auto-antibodies against IL-23 in all patients without any positive findings, confirming a previous report (48). All patients included in our study present auto-antibodies against INF $\omega$, and about $60 \%$ have auto-antibodies against IL-22. To speculate, these auto-antibodies may influence the difference in immune response found in whole blood by interacting in autocrine and paracrine signaling loops and thereby disturb cellular responses. These speculations are supported by the finding that APS-1 patients failed to up-regulate the interferon regulated serum inflammation marker B2M after C. albicans stimulation. The inhibition of interferon regulated genes by APS-1 patient auto-antibodies is well established (49), and the importance of type I interferons in immunity against Candida was recently demonstrated (50).

Our study has some limitations. First, the rarity of APS-1 makes biological samples limited. We therefore had to strictly prioritize our samples and chose to focus on stimulation assays in the search of differences in the protein expression using flow cytometry, rather than for example detecting RNA transcripts using quantitative polymerase chain reactions. Our cell assays were also more robust compared to pilot experiments of culturing PBMCs or whole blood with $C$. albicans, and analyzing supernatants for signaling molecules using ELISA. Second, in our cell assay, few monocytes produced IL-23p19 when stimulated with curdlan and some cells were border line positive for IL-23p19 after stimulation. However, we carefully optimized our assay regarding incubation time, concentration of Dectin, and Brefeldin A stimulation. Moreover, samples from two patients and two controls were always stimulated and analyzed together, we used a consistent gating strategy when analyzing data, and our findings regarding IL-23 were comparable in both the cell assay and the TrueCulture system. In general, whole blood assays probably mirror the in vivo conditions of inflammation more precisely than PBMC assays regarding interplay between subsets of immune cells and mediators. 
We found significantly altered IL-23p19/IL-23 signaling in both our assays making the findings reliable.

In summary, in order to gain further insights into the molecular mechanisms of CMC in APS-1, we used different approaches to investigate the immune activation in APS-1 in response to $C$. albicans. Our findings indicate that patients have a significant altered immune activation with broad implications on the quality of the immune response to C. albicans and that monocytes contribute to a dysregulation of the IL-23/Th17 axis, which is crucial for proper immunity to fungal infections.

\section{ETHICS STATEMENT}

This study was carried out in accordance with the recommendations of The Regional Committee for Medical and Health Research Ethics with written informed consent from all subjects. All subjects gave written informed consent in accordance with the Declaration of Helsinki. The protocol was approved by The Regional Committee for Medical and Health Research Ethics.

\section{AUTHOR CONTRIBUTIONS}

$\varnothing \mathrm{B}, \mathrm{EB}, \mathrm{AW}$, and $\mathrm{BO}$ collected samples and clinical information. $\varnothing \mathrm{B}, \mathrm{HR}$, and ND did the statistical and bioinformatical analyses. $\varnothing \mathrm{B}, \mathrm{EB}$, and $\mathrm{AH}$ executed the cell experiments. All authors

\section{REFERENCES}

1. Perheentupa J.Autoimmune polyendocrinopathy-candidiasis-ectodermal dystrophy. JClin Endocrinol Metab (2006) 91(8):2843-50. doi:10.1210/ jc.2005-2611

2. Husebye ES, Perheentupa J, Rautemaa R, Kampe O. Clinical manifestations and management of patients with autoimmune polyendocrine syndrome type I. J Intern Med (2009) 265(5):514-29. doi:10.1111/j.13652796.2009.02090.x

3. Soderbergh A, Myhre AG, Ekwall O, Gebre-Medhin G, Hedstrand H, Landgren E, et al. Prevalence and clinical associations of 10 defined autoantibodies in autoimmune polyendocrine syndrome type I. J Clin Endocrinol Metab (2004) 89(2):557-62. doi:10.1210/jc.2003-030279

4. Bruserud O, Oftedal BE, Landegren N, Erichsen M, Bratland E, Lima K, et al. A longitudinal follow-up of autoimmune polyendocrine syndrome type 1. J Clin Endocrinol Metab (2016) 101(8):2975-83. doi:10.1210/jc.2016-1821

5. Wolff AS, Sarkadi AK, Marodi L, Karner J, Orlova E, Oftedal BE, et al. Anti-cytokine autoantibodies preceding onset of autoimmune polyendocrine syndrome type I features in early childhood. J Clin Immunol (2013) 33(8):1341-8. doi:10.1007/s10875-013-9938-6

6. Nagamine K, Peterson P, Scott HS, Kudoh J, Minoshima S, Heino M, et al. Positional cloning of the APECED gene. Nat Genet (1997) 17(4):393-8. doi:10.1038/ng1297-393

7. Finnish-German APECED Consortium. An autoimmune disease, APECED, caused by mutations in a novel gene featuring two PHD-type zinc-finger domains. Nat Genet (1997) 17(4):399-403. doi:10.1038/ng1297-399

8. Bruserud O, Oftedal BE, Wolff AB, Husebye ES. AIRE-mutations and autoimmune disease. Curr Opin Immunol (2016) 43:8-15. doi:10.1016/j.coi. 2016.07.003

9. Pitkanen J, Vahamurto P, Krohn K, Peterson P. Subcellular localization of the autoimmune regulator protein. Characterization of nuclear targeting and transcriptional activation domain. J Biol Chem (2001) 276(22):19597-602. doi:10.1074/jbc.M008322200

10. Anderson MS, Venanzi ES, Klein L, Chen Z, Berzins SP, Turley SJ, et al. Projection of an immunological self shadow within the thymus by the AIRE protein. Science (2002) 298(5597):1395-401. doi:10.1126/science.1075958 contributed in writing the manuscript and have approved the final version.

\section{ACKNOWLEDGMENTS}

The technical assistance from Elin Theodorsen, Hajirah Muneer, and Elisabeth Halvorsen are highly appreciated.

\section{FUNDING}

This work was supported by the University of Bergen, the Bergen Medical Research Foundation (ND) and the Broegelmann Foundation (ND).

\section{SUPPLEMENTARY MATERIAL}

The Supplementary Material for this article can be found online at http://journal.frontiersin.org/article/10.3389/fimmu.2017.01074/ full\#supplementary-material.

FIGURE S1 | Functional annotation of the protein profile characterizing the altered immune response to $C$. albicans in APS-1 patients versus healthy individuals. This protein:gene-ontology-(GO) term network identified four clusters of biological processes, each with its leading term, that most efficiently interconnect the nine proteins here relevant. Any regulatory relationships between the proteins, as per CluePedia v10.0 are displayed as well.

FIGURE S2 | Gating strategy for flow cytometric analyses.

11. Yang S, Fujikado N, Kolodin D, Benoist C, Mathis D. Immune tolerance Regulatory $\mathrm{T}$ cells generated early in life play a distinct role in maintaining self-tolerance. Science (2015) 348(6234):589-94. doi:10.1126/science.aaa7017

12. Odds FC. Candida and Candidosis. 2nd ed. London: Bailliere-Tindall (1988).

13. Kisand K, Peterson P. Autoimmune polyendocrinopathy candidiasis ectodermal dystrophy: known and novel aspects of the syndrome. Ann N Y Acad Sci (2011) 1246:77-91. doi:10.1111/j.1749-6632.2011.06308.x

14. Meloni A, Willcox N, Meager A, Atzeni M, Wolff AS, Husebye ES, et al. Autoimmune polyendocrine syndrome type 1: an extensive longitudinal study in Sardinian patients. J Clin Endocrinol Metab (2012) 97(4):1114-24. doi:10.1210/jc.2011-2461

15. Orlova EM, Bukina AM, Kuznetsova ES, Kareva MA, Zakharova EU, Peterkova VA, et al. Autoimmune polyglandular syndrome type 1 in Russian patients: clinical variants and autoimmune regulator mutations. Horm Res Paediatr (2010) 73(6):449-57. doi:10.1159/000313585

16. Rosatelli MC, Meloni A, Meloni A, Devoto M, Cao A, Scott HS, et al. A common mutation in Sardinian autoimmune polyendocrinopathy-candidiasis-ectodermal dystrophy patients. Hum Genet (1998) 103(4):428-34. doi:10.1007/ s004390050846

17. Ferre EM, Rose SR, Rosenzweig SD, Burbelo PD, Romito KR, Niemela JE, et al. Redefined clinical features and diagnostic criteria in autoimmune polyendocrinopathy-candidiasis-ectodermal dystrophy. JCI Insight (2016) 1(13):e88782. doi:10.1172/jci.insight. 88782

18. Kagami S, Rizzo HL, Kurtz SE, Miller LS, Blauvelt A. IL-23 and IL-17A, but not IL-12 and IL-22, are required for optimal skin host defense against Candida albicans. J Immunol (2010) 185(9):5453-62. doi:10.4049/jimmunol.1001153

19. Puel A, Doffinger R, Natividad A, Chrabieh M, Barcenas-Morales G, Picard C, et al. Autoantibodies against IL-17A, IL-17F, and IL-22 in patients with chronic mucocutaneous candidiasis and autoimmune polyendocrine syndrome type I. J Exp Med (2010) 207(2):291-7. doi:10.1084/jem.20091983

20. Kisand K, Boe Wolff AS, Podkrajsek KT, Tserel L, Link M, Kisand KV, et al. Chronic mucocutaneous candidiasis in APECED or thymoma patients correlates with autoimmunity to Th17-associated cytokines. JExp Med (2010) 207(2):299-308. doi:10.1084/jem.20091669

21. Wolff AS, Erichsen MM, Meager A, Magitta NF, Myhre AG, Bollerslev J, et al. Autoimmune polyendocrine syndrome type 1 in Norway: phenotypic 
variation, autoantibodies, and novel mutations in the autoimmune regulator gene. J Clin Endocrinol Metab (2007) 92(2):595-603. doi:10.1210/jc.2006-1873

22. Myhre AG, Halonen M, Eskelin P, Ekwall O, Hedstrand H, Rorsman F, et al. Autoimmune polyendocrine syndrome type 1 (APS I) in Norway. Clin Endocrinol (2001) 54(2):211-7. doi:10.1046/j.1365-2265.2001.01201.x

23. Stavrum AK, Petersen K, Jonassen I, Dysvik B. Analysis of geneexpression data using J-express. Curr Protoc Bioinformatics (2008) 7:7.3. doi:10.1002/0471250953.bi0703s21

24. Bindea G, Galon J, Mlecnik B. CluePedia Cytoscape plugin: pathway insights using integrated experimental and in silico data. Bioinformatics (2013) 29(5):661-3. doi:10.1093/bioinformatics/btt019

25. Smoot ME, Ono K, Ruscheinski J, Wang PL, Ideker T. Cytoscape 2.8: new features for data integration and network visualization. Bioinformatics (2011) 27(3):431-2. doi:10.1093/bioinformatics/btq675

26. Laakso SM, Kekalainen E, Rossi LH, Laurinolli TT, Mannerstrom H, Heikkila N, et al. IL-7 dysregulation and loss of CD8+ T cell homeostasis in the monogenic human disease autoimmune polyendocrinopathy-candidiasisectodermal dystrophy. J Immunol (2011) 187(4):2023-30. doi:10.4049/ jimmunol.1100212

27. Netea MG, Joosten LA, van der Meer JW, Kullberg BJ, van de Veerdonk FL. Immune defence against Candida fungal infections. Nat Rev Immunol (2015) 15(10):630-42. doi:10.1038/nri3897

28. Nicola AM, Casadevall A, Goldman DL. Fungal killing by mammalian phagocytic cells. Curr Opin Microbiol (2008) 11(4):313-7. doi:10.1016/j. mib.2008.05.011

29. Romani L. Immunity to fungal infections. Nat Rev Immunol (2011) 11(4): 275-88. doi:10.1038/nri2939

30. Ma X, Yan W, Zheng H, Du Q, Zhang L, Ban Y, et al. Regulation of IL-10 and IL-12 production and function in macrophages and dendritic cells. F1000Res (2015) 4:F1000 Faculty Rev-1465. doi:10.12688/f1000research.7010.1

31. Trinchieri G. Interleukin-12: a cytokine produced by antigen-presenting cells with immunoregulatory functions in the generation of T-helper cells type 1 and cytotoxic lymphocytes. Blood (1994) 84(12):4008-27.

32. Oppmann B, Lesley R, Blom B, Timans JC, Xu Y, Hunte B, et al. Novel p19 protein engages IL-12p40 to form a cytokine, IL-23, with biological activities similar as well as distinct from IL-12. Immunity (2000) 13(5):715-25. doi:10.1016/S1074-7613(00)00070-4

33. Ahlgren KM, Moretti S, Lundgren BA, Karlsson I, Ahlin E, Norling A, et al. Increased IL-17A secretion in response to Candida albicans in autoimmune polyendocrine syndrome type 1 and its animal model. Eur J Immunol (2011) 41(1):235-45. doi:10.1002/eji.200939883

34. Ng WF, von Delwig A, Carmichael AJ, Arkwright PD, Abinun M, Cant AJ, et al. Impaired $\mathrm{T}(\mathrm{H}) 17$ responses in patients with chronic mucocutaneous candidiasis with and without autoimmune polyendocrinopathycandidiasis-ectodermal dystrophy. J Allergy Clin Immunol (2010) 126(5): 1006-15, 15.e1-4. doi:10.1016/j.jaci.2010.08.027

35. Catana CS, Berindan Neagoe I, Cozma V, Magdas C, Tabaran F, Dumitrascu DL. Contribution of the IL-17/IL-23 axis to the pathogenesis of inflammatory bowel disease. World J Gastroenterol (2015) 21(19):5823-30. doi:10.3748/wjg.v21.i19.5823

36. Suzuki E, Mellins ED, Gershwin ME, Nestle FO, Adamopoulos IE. The IL-23/ IL-17 axis in psoriatic arthritis. Autoimmun Rev (2014) 13(4-5):496-502. doi:10.1016/j.autrev.2014.01.050

37. Yeremenko N, Paramarta JE, Baeten D. The interleukin-23/interleukin17 immune axis as a promising new target in the treatment of spondyloarthritis. Curr Opin Rheumatol (2014) 26(4):361-70. doi:10.1097/bor. 0000000000000069

38. Wang Q, Franks HA, Porte J, El Refaee M, Shah S, Crooks J, et al. Novel approach for interleukin-23 up-regulation in human dendritic cells and the impact on T helper type 17 generation. Immunology (2011) 134(1): 60-72. doi:10.1111/j.1365-2567.2011.03467.x
39. Ryan KR, Hong M, Arkwright PD, Gennery AR, Costigan C, Dominguez M, et al. Impaired dendritic cell maturation and cytokine production in patients with chronic mucocutanous candidiasis with or without APECED. Clin Exp Immunol (2008) 154(3):406-14. doi:10.1111/j.1365-2249.2008. 03778.x

40. Hong M, Ryan KR, Arkwright PD, Gennery AR, Costigan C, Dominguez M, et al. Pattern recognition receptor expression is not impaired in patients with chronic mucocutanous candidiasis with or without autoimmune polyendocrinopathy candidiasis ectodermal dystrophy. Clin Exp Immunol (2009) 156(1):40-51. doi:10.1111/j.1365-2249.2009.03873.x

41. Wolff AS, Oftedal BE, Kisand K, Ersvaer E, Lima K, Husebye ES. Flow cytometry study of blood cell subtypes reflects autoimmune and inflammatory processes in autoimmune polyendocrine syndrome type I. Scand J Immunol (2010) 71(6):459-67. doi:10.1111/j.1365-3083.2010.02397.x

42. de Beaucoudrey L, Samarina A, Bustamante J, Cobat A, Boisson-Dupuis S, Feinberg J, et al. Revisiting human IL-12Rbetal deficiency: a survey of 141 patients from 30 countries. Medicine (2010) 89(6):381-402. doi:10.1097/ MD.0b013e3181fdd 832

43. Prando C, Samarina A, Bustamante J, Boisson-Dupuis S, Cobat A, Picard C, et al. Inherited IL-12p40 deficiency: genetic, immunologic, and clinical features of 49 patients from 30 kindreds. Medicine (2013) 92(2):109-22. doi:10.1097/MD.0b013e31828a01f9

44. Hsu AP, McReynolds LJ, Holland SM. GATA2 deficiency. Curr Opin Allergy Clin Immunol (2015) 15(1):104-9. doi:10.1097/aci.0000000000000126

45. Pedroza LA, Kumar V, Sanborn KB, Mace EM, Niinikoski H, Nadeau K, et al. Autoimmune regulator (AIRE) contributes to Dectin-1-induced TNF-alpha production and complexes with caspase recruitment domaincontaining protein 9 (CARD9), spleen tyrosine kinase (Syk), and Dectin-1. J Allergy Clin Immunol (2012) 129(2):464-72, 72.e1-3. doi:10.1016/j. jaci.2011.08.027

46. Peterson P, Org T, Rebane A. Transcriptional regulation by AIRE: molecular mechanisms of central tolerance. Nat Rev Immunol (2008) 8(12):948-57. doi: $10.1038 /$ nri2450

47. Hubert FX, Kinkel SA, Webster KE, Cannon P, Crewther PE, Proeitto AI, et al. A specific anti-AIRE antibody reveals AIRE expression is restricted to medullary thymic epithelial cells and not expressed in periphery. J Immunol (2008) 180(6):3824-32. doi:10.4049/jimmunol.180.6.3824

48. Karner J, Pihlap M, Ranki A, Krohn K, Trebusak Podkrajsek K, Bratanic N, et al. IL-6-specific autoantibodies among APECED and thymoma patients. Immun Inflamm Dis (2016) 4(2):235-43. doi:10.1002/iid3.109

49. Kisand K, Link M, Wolff AS, Meager A, Tserel L, Org T, et al. Interferon autoantibodies associated with AIRE deficiency decrease the expression of IFN-stimulated genes. Blood (2008) 112(7):2657-66. doi:10.1182/blood-200803-144634

50. Smeekens SP, Ng A, Kumar V, Johnson MD, Plantinga TS, van Diemen C, et al. Functional genomics identifies type I interferon pathway as central for host defense against Candida albicans. Nat Commun (2013) 4:1342. doi:10.1038/ncomms 2343

Conflict of Interest Statement: The authors declare that the research was conducted in the absence of any commercial or financial relationships that could be construed as a potential conflict of interest.

Copyright (® 2017 Bruserud, Bratland, Hellesen, Delaleu, Reikvam, Oftedal and Wolff. This is an open-access article distributed under the terms of the Creative Commons Attribution License (CC BY). The use, distribution or reproduction in other forums is permitted, provided the original author(s) or licensor are credited and that the original publication in this journal is cited, in accordance with accepted academic practice. No use, distribution or reproduction is permitted which does not comply with these terms. 